\title{
Special weathering steel, a contribution to environmental protection
}

\author{
E. S. Ayllón \\ Department of Materials Science and Technique \\ (Departamento Ciencia y Técnica de Materiales) - CITEFA, \\ V. Martelli, Argentina
}

\begin{abstract}
The term weathering steels describes a class of low-alloy structural steels that develop an adherent protective rust layer, called patina, during exposure to the atmosphere. As a result of this, weathering steels, unlike ordinary plain carbon steels, do not require painting, which means important advantages: avoiding associated costs of initial painting, periodic repainting, containment and disposal of blasting debris during repainting.

The development of the protective patina depends on the steel microalloying elements which it contains, consequently, the corrosion process destroys a certain amount of steel in order to supply the microalloying elements. However, only part of all the $\mathrm{Fe}$ involved in this process gets into the patina. In fact, a percentage of $\mathrm{Fe}$ in the form of soluble corrosion products is swept away by the rainwater or dew, staining other materials with rough surfaces on the structures.

The completion of the protective patina takes at least several years.

In order to analyse the influence of non-metallic inclusions morphology and composition on the initial stages of the corrosive atmospheric attack, an experimental steel called PA (P: patina-A: acceleration) was designed.

A great quantity of non-metallic inclusions with spherical morphology, great chemical reactivity and very small size was chosen. Considering the structural behaviour, this morphology is advisable since it produces a greater isotropy of the mechanical properties.

Experimental samples of PA steel were tested in outdoors exposure producing, in only one year, a very effective passive patina. Consequently it can be observed that these tests clearly showed a vanishing effect of all staining contaminant products, which means an outstanding advantage towards the environmental protection.
\end{abstract}




\section{Introduction}

The development of the passivity depends on the steel microalloying elements in the patina, which leads to the destruction of a certain amount of steel to form the magnetite and patina main components $(\alpha, \beta, \gamma$, and $\delta \mathrm{FeOOH})$. However, not all the $\mathrm{Fe}$ involved in this process gets into the patina. In fact, a percentage of $\mathrm{Fe}$ in the form of soluble corrosion products is swept away by the rainwater or dew, generally producing an unpleasant effect when staining other materials with rough surface on weathering steel structures.

This happens, for instance, in the concrete foundations of bridges, viaducts and high-tension towers. Since they are built with a porous material, the corrosion products are trapped.

Several solutions have been proposed to avoid product corrosion stains the formerly mentioned materials. Nevertheless, they did not meet he expectations.

In previous works, the detrimental effect of sulphur in the corrosion resistance of steels was highlighted. The non-metallic inclusions formed by this element and the manganese are plastically deformed at steel rolling temperatures, thus showing the inclusions and elongated morphology in the rolling direction, having the metal an anisotropy of the mechanical properties. This is quantified by tension tests, whose striction and strain results differ when the tests are carried out in the direction of the rolling or perpendicular to the already mentioned rolling. Charpy impact values change and the bending test on mandrel shows cracks when it is carried out in the direction of the $\mathrm{MnS}$ elongated inclusions chains.

There is a remarkable improvement when the morphology of the non-metallic inclusions is modified, thus substituting the elongated structure chains for a spherical spatial uniform distribution [1].

As it was reported in previous works, the nucleation of steel atmospheric corrosion is related to non-metallic inclusions, particularly to the $\mathrm{MnS}$ ones [2].

The change proposed to improve the mechanical properties outlines its possible influence on the nucleation of the atmospheric corrosion, on the patina formation and protective attributes.

Previous results verified by optical microscopy, electron scanning, and electron probe microanalysis showed that the addition of rare earths modifies steel behaviour towards atmospheric corrosion because of the different chemical composition of the non-metallic inclusions developed in the process.

Furthermore, and according to the Group IIIA element of the Periodic Table, a difference in the behaviour was also found, which was used as a non-metallic inclusions modifier. The Free Energy $\left(\Delta \mathrm{G}^{\circ}\right)$ of the CeS formation is lower than the CeO's, coinciding with the fact that both of them were stable in the air at environmental temperature. The La thermodynamic values are higher than Ce's, and show that oxidation is benefited under the same environmental conditions.

A. Szummer and M. Janik-Czachor [3] point out that the presence of nonmetallic inclusions, which were morphological modified by rare earths, is detrimental for corrosion resistance, and that the $\mathrm{CeS}$ attack nucleating effect is bigger than the MnS one, usually found in steels. 


\section{PA steel formulation}

According to the above mentioned, the conclusion is that a formulation containing the necessary microalloying elements to produce the corrosion product film of a steel $(\mathrm{Cu}, \mathrm{Cr}$, and $\mathrm{Si})$ and non-metallic inclusions - modified by rare earths additions (particularly $\mathrm{Ce}$ ) - is considered to join both criteria: weatherability and better mechanical properties.

Following these criteria, it was planned a weathering steel experimental tapping with the addition of rare earths as modifiers of non-metallic inclusions from their morphological as well as from their chemical reactivity point of view.

A minimum $\mathrm{C}$ content was planned to provide the mechanical strength and ferritic attribute of structural steels. The percentage of the main microalloying elements, $\mathrm{Cu}$ and $\mathrm{Cr}$, were fixed on practical basis. The available ferroalloys for steel production were considered as well as their use under the fusion conditions to be adopted. The recommendations given by specialised literature were used for the rare earths percentage and addition process to the ladle [4].

The percentage of $\mathrm{Ni}$ added - almost similar to the Cu's percentage - is the suggested one to neutralise the detrimental effect of the latter in the hot-rolled process, widely known as hot shortness. The vanadium - together with the aluminium - is a ferritic grain-refining agent. Due to its availability and easiness to operate, the rare earths silicide was adopted (Fe: 35\%; Si:31\%; and Rare Earths: $34 \%$; with a Ce composition of: $50 \%$; La:25\%; Nd: $10 \%$; and $\operatorname{Pr}: 5 \%$ ) in a percentage of $1.0 \mathrm{~g} / \mathrm{kg}$ of melting steel as a means of containing these rare earths.

The chemical composition of steel - analysed in the hot-rolled product - in comparison with the one of the presently produced Cor Ten A and QST-52 nonalloyed steel is shown in Table 1 .

Table 1: Chemical composition of hot-rolled PA steel, Cor Ten A steel and QST-52 non-alloyed steels used as a reference samples.

\begin{tabular}{|c|c|c|c|c|c|c|c|c|c|c|c|c|}
\hline Steel & $\mathrm{C}$ & $\mathbf{S i}$ & Mn & $\mathbf{P}$ & $\mathbf{S}$ & $\mathrm{Cu}$ & $\mathrm{Cr}$ & $\mathbf{N i}$ & Al & Sn & As & $\mathbf{V}$ \\
\hline $\begin{array}{l}\text { PA } \\
\text { Cor }\end{array}$ & 0.15 & 0.41 & 1.01 & 0.086 & 0.105 & 0.46 & 1.0 & 0.38 & 0.021 & 0.01 & 0.013 & 0.006 \\
\hline Ten A & 0.10 & 0.36 & 0.34 & 0.093 & 0.018 & 0.31 & 0.60 & 0.12 & ------- & ----- & 0.005 & 0.008 \\
\hline QST-52 & 0.16 & 0.36 & 1.36 & 0.013 & 0.035 & 0.05 & 0.07 & 0.06 & -------- & ----- & ------- & -----.- \\
\hline
\end{tabular}

An induction furnace was used and 4 ingots of $60 \mathrm{~kg}$ net were tapped (without dead heads). The final temperature of the process after a careful bath deoxidisation by $\mathrm{Mn}, \mathrm{Al}$ and $\mathrm{Si}$ addition was of $1673^{\circ} \mathrm{C}$ in the furnace and of $1620^{\circ} \mathrm{C}$ in the ladle. The temperature of this process was between 1590 and $1600^{\circ} \mathrm{C}$.

After the tapping, the ingots were heated again at a rolling initial temperature of $1150^{\circ} \mathrm{C}$. The final rolling temperature was between $950-1000^{\circ} \mathrm{C}$. The final thickness was of $3.5 \mathrm{~mm}$ and the hardness was $283 \mathrm{H}_{\mathrm{B}}$. 
Upon completion of the rolling, the steel underwent a thermal treatment process to set the mechanical properties to the usually recommended ones under the Cor Ten A steel specifications (ASTM A-588 and A-242).

- Austenitised treatment: $\mathrm{T}=870 / 880^{\circ} \mathrm{C}$ for 10 minutes.

- Water cooling at room temperature.

- Tempering at $750^{\circ} \mathrm{C}$ for 1 hour.

- Cooling inside furnace up to $400^{\circ} \mathrm{C}$, then to the air.

- Final hardness of $\mathrm{H}_{\mathrm{B}}=160$, equal to a resistance to rupture of $53 \mathrm{~kg} \cdot \mathrm{mm}^{-2}$ (52 MPa).

One of the ingots was cold-rolled. Its final thickness was $2 \mathrm{~mm}$, obtained from 10 times in the rolling machine (at 0.15 each time, starting from a hotrolled thickness of $3.5 \mathrm{~mm}$.).

\section{Open air exposure test}

Long-lasting tests were carried out in the urban site of VILLA MARTELLI outdoor test station and in the rural site of IGUAZU station. Specimens were obtained from the hot-rolled material at $3.5 \mathrm{~mm}$ thickness and from the coldrolled material at $2 \mathrm{~mm}$ thickness with $45 \mathrm{~mm}$ wide and $300 \mathrm{~mm}$ long. Holes with a diameter of $22 \mathrm{~mm}$ were made to set the samples in the same frame insulators, which were used for the previous tests [5] (Figure 1). The superficial preparation was the sanding up to Sa3 grade of SIS 055900 STANDARD (1967) and weighing the samples. Three samples exposed at 3, 6, 9, 12, 18, 24, $30,36,42,48$, and 60 months were removed each time, and after measuring their electrochemical potential in situ [6] they were weighed (increased weight).

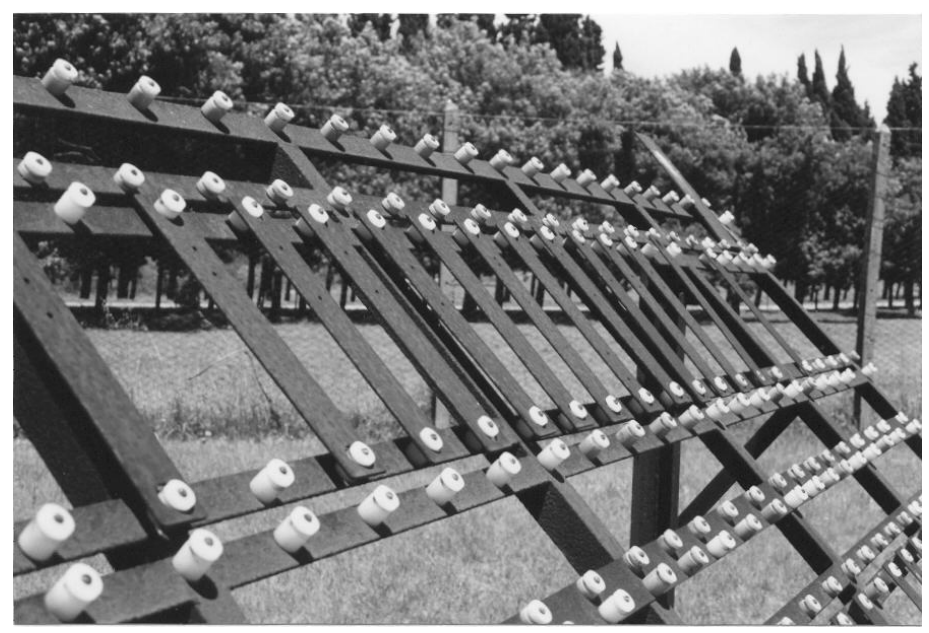

Figure 1: $\quad$ PA steel outdoor test in VILLA MARTELLI urban site. 
Then, an acid pickling was carried out at $80^{\circ} \mathrm{C}$ in a $\mathrm{HCl}$ solution $(50 \%)$ with urotropine $(0.1 \%)$ as inhibitor of the steel attack. The samples were weighted at intervals of 10 minutes each until achieving almost linear weight variations between 30 and 50 minutes, according to DP/8407 ISO standard. The $\Delta \mathrm{W}(\mathrm{g})$ value was determined by the intersection of the line obtained by linear regression by minimum squares with the vertical axis (Figure 2) [7].

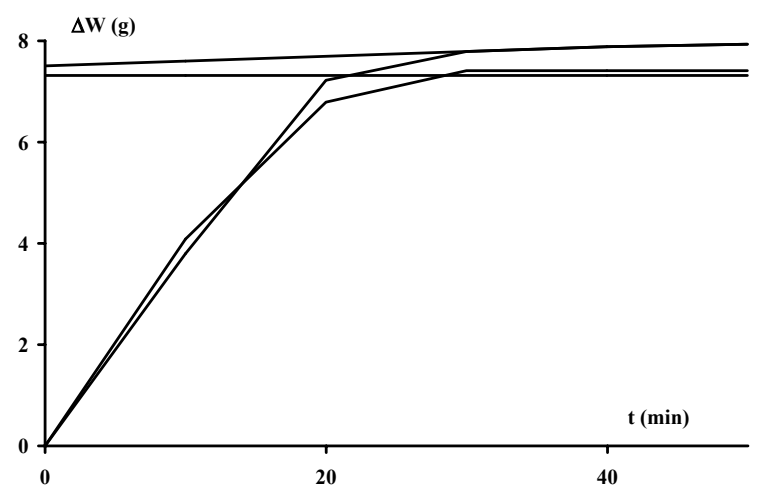

Figure 2: Weight loss based on pickling time, and pertinent linear regression.

Three hot-rolled PA steel specimens exposed for 5 years in VILLA MARTELLI station.

The results were graphically represented from (1).

$$
\Delta W=k \cdot t^{n}
$$

$k$ and $n$ constants were determined from experimental data by regression analysis; results are shown in Table 2.

Table 2: $\quad \mathrm{k}$ and $\mathrm{n}$ constants of the linear regression.

\begin{tabular}{|c|c|c|c|c|}
\hline Steel & Thickness & & Urban Site & Subtropical Site \\
\hline \multirow[b]{2}{*}{ PA HR } & \multirow[b]{2}{*}{$3 \mathrm{~mm}$} & $\mathrm{k}$ & 1.2177 & 0.8054 \\
\hline & & $\mathrm{n}$ & 0.1652 & 0.2354 \\
\hline \multirow[b]{2}{*}{ PA CR } & \multirow[b]{2}{*}{$2 \mathrm{~mm}$} & $\mathrm{k}$ & 1.9232 & 1.057 \\
\hline & & $\mathrm{n}$ & 0.3641 & 0.8232 \\
\hline
\end{tabular}

HR: Hot-rolled CR: Cold-rolled.

$\mathrm{k}$ coefficient represents the weight loss corresponding to 1 year of exposure. As regards the initial stage of the atmospheric corrosion, the comparison between both values reveals a greater aggressiveness in the urban site than in the 
rural site. $\mathrm{n}$ exponent values for hot-rolled PA steel are lower than Cor Ten A values and QST 52 non-weathering steel values, which were determined in previous tests [5] (Figures 3 and 4).

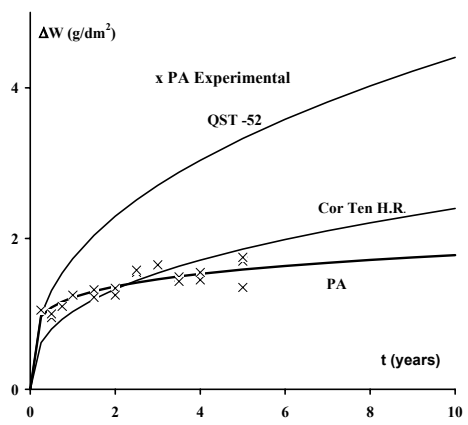

Figure 3: Time-based weight loss of hot-rolled PA steel, extrapolated at 10 years. Urban site.

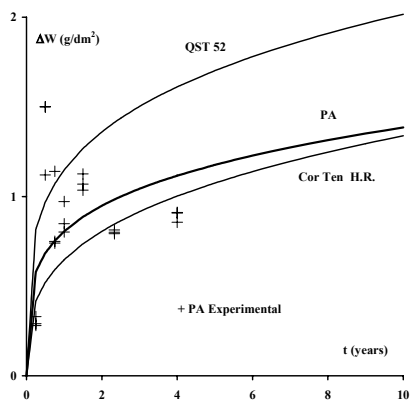

Figure 4: Time-based weight loss of cold-rolled PA steel, extrapolated at 10 years. Subtropical site.

Figures 5 to 8 show the $\Delta W(\mathrm{~g})$ weight loss on the basis of the weight of the corrosion products that form the patina as well as the line of experimental data obtained by linear regression in VILLA MARTELLI urban site. In those same figures, we can see two lines passing through the coordinate origin, which correspond to two extreme cases of patina chemical composition. If all the Fe dissolved in the corrosive process had combined and formed $\mathrm{FeOOH}$, the representative points would have met on the lowest slope line; if it had been fully combined forming magnetite, they would have met on the highest slope line with respect to the horizontal axis.

Since a mixture of the two compounds forms the patinas, the representative points should meet in the area between these two boundaries, [8].

The abscissa difference between the line resulting from linear regression of experimental data, and the lines pertaining to $\mathrm{Fe}_{3} \mathrm{O}_{4}$ and $\mathrm{FeOOH}$ gives us the 
extreme values of the corrosion products weight loss by rain wash. If we compare this experimental result with the results of the hot-rolled Cor Ten A steel and QST - 52 steel (Figures 7 and 8) [5], we will notice that there is a decrease of the corrosion products that are let loose among PA steel, Cor Ten A steel and non-weathering steel, when they are exposed to the open air.

The metal weight swept away by dew or rain-wash may be estimated as follows:

The abscissa difference between the line obtained by regression from $\Delta \mathrm{W}(\mathrm{g})$ experimental data, and the one corresponding to the $\mathrm{FeOOH}$ line $\left(W_{c}(\mathrm{~g})\right)-$ as the most unfavourable case- represents the weight loss by $\Delta W_{L}$ wash:

$$
\Delta W_{L}=W_{c}-W_{P}
$$

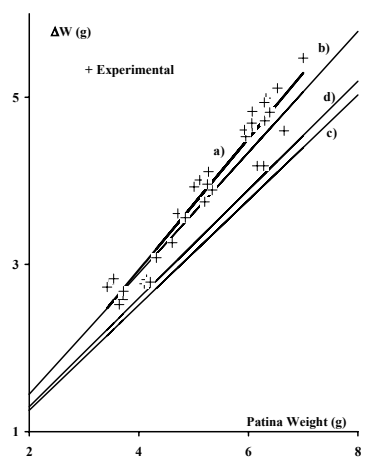

Figure 5: Hot-rolled PA steel in urban site; a) Regression; b) $\mathrm{Fe}_{3} \mathrm{O}_{4}$; c) $\mathrm{FeOOH}$; d) $0.925 \mathrm{FeOOH}+0.075 \mathrm{Fe}_{3} \mathrm{O}_{4}$.

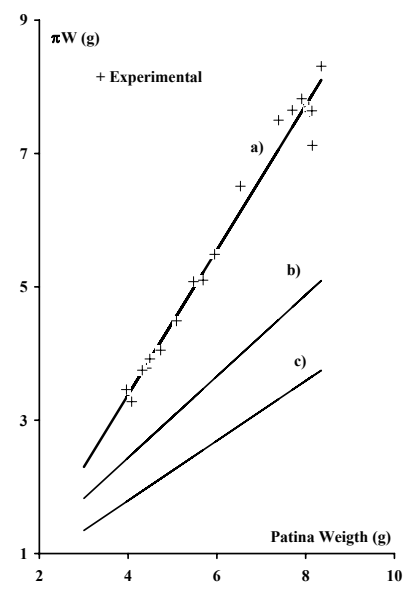

Figure 6: Cold-rolled PA steel in urban site; a) Regression; b) $\mathrm{Fe}_{3} \mathrm{O}_{4}$; c) $\mathrm{FeOOH}$. 


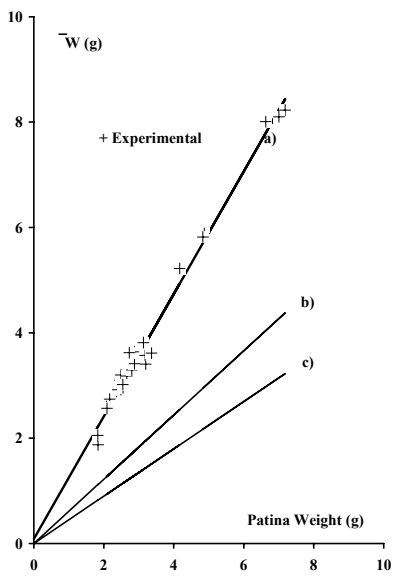

Figure 7: Hot-rolled Cor Ten A steel in urban site; a) Regression; b) $\mathrm{Fe}_{3} \mathrm{O}_{4}$; c) $\mathrm{FeOOH}$.

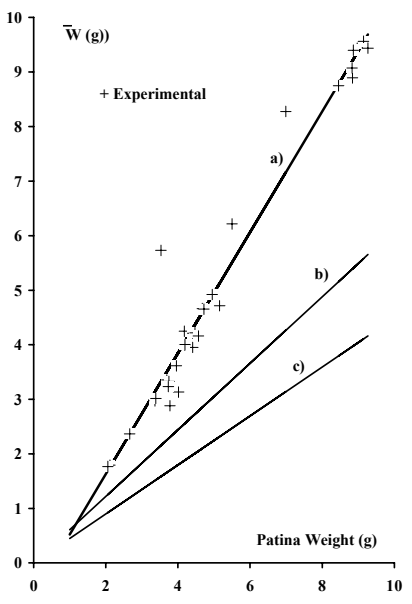

Figure 8: Hot-rolled QST - 52 steel in urban site; a) Regression; b) $\mathrm{Fe}_{3} \mathrm{O}_{4}$; c) $\mathrm{FeOOH}$.

Considering as abscissas the previous ordinates and vice versa:

$$
\Delta W_{L}=\left(b_{c}-b_{P}\right) \Delta W
$$

where: $\mathrm{b}_{\mathrm{c}}$ is the angular coefficient with respect to the $\Delta W(\mathrm{~g})$ vertical axis of the $\mathrm{FeOOH}$ line; $\mathrm{b}_{\mathrm{p}}$ is the angular coefficient with respect to the $\Delta W(\mathrm{~g})$ vertical axis of the line obtained by regression from experimental data; and $\Delta W$ (g) is the weight loss of the specimens. 
According to (1)

$$
\Delta W\left(\frac{g}{d m^{2}}\right)=\frac{\Delta W(g)}{A\left(d m^{2}\right)}=k \cdot t^{n}
$$

A $\left(\mathrm{dm}^{2}\right)$ represents the specimen area exposed to the open air. $\mathrm{k}$ and $\mathrm{n}$ : Regression coefficients. They depend on the outdoor exposure site and the material.

Substituting (2)

$$
\Delta W_{L}=\left(b_{c}-b_{p}\right) \cdot A \cdot k \cdot t^{n}=K \cdot t^{n}
$$

The values for the calculus are shown in Table 3, and results in Figure 9, where a) $\Delta \mathrm{W}$ Cor Ten A; b) $\Delta \mathrm{W}$ PA HR; c) $\Delta \mathrm{W}_{\mathrm{L}}$ Cor Ten A; d) $\Delta \mathrm{W}_{\mathrm{L}}$ PA HR

The variation of the weight loss $\Delta \mathrm{W}_{\mathrm{L}}$ with respect to time:

$$
\frac{d}{d t} \Delta W_{L}=n K_{t}(n-1)
$$

\begin{tabular}{|c|c|c|c|c|c|c|c|}
\hline Steel & $\boldsymbol{k}$ & $n$ & $A\left(\mathrm{dm}^{2}\right)$ & $\boldsymbol{b}_{c}$ & $b_{p}$ & $K$ & $n K$ \\
\hline & \multicolumn{7}{|c|}{ Urban Site } \\
\hline $\begin{array}{l}\text { PA. HR } \\
\end{array}$ & 1.2173 & .1652 & 2.87 & 1.5910 & 1.2834 & 1.0746 & 0.1775 \\
\hline PA. CR & & & 3.01 & 1.5910 & 0.9522 & 3.6979 & 1.3664 \\
\hline \multirow[t]{2}{*}{$\begin{array}{l}\text { Cor Ten } \\
\text { A HR }\end{array}$} & 1.2734 & 0.1901 & 3.00 & 1.5910 & 0.8598 & 0.8598 & 0.5310 \\
\hline & \multicolumn{7}{|c|}{ Subtropical Site } \\
\hline & 8054 & 4 & 2.87 & 1.5910 & 1.0588 & 1.2302 & 0.2896 \\
\hline A CR & 1.057 & 0.8232 & 3.01 & 1.5910 & 1.1378 & 1.4419 & 1.1870 \\
\hline
\end{tabular}

Table 3: $\quad$ Values for the graphic representation of (3) and (4).

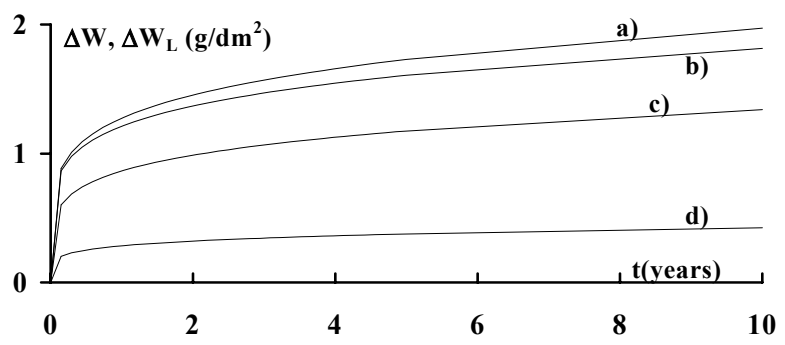

Figure 9: Total weight loss and the corresponding one to dew and/or rainwash in urban site.

\section{Conclusions}

In order to obtain acceleration in the formation of the patina, the goal was to increase the intensity of the initial attack, first year of atmospheric exposition. 
This aim was achieved through an increase of a non-metallic inclusions density with spherical morphology, great chemical reactivity and very small size of them.

Non-metallic inclusions modified by rare earths additions, particularly $\mathrm{Ce}$, were considered to join: weatherability and better mechanical properties.

Experimental samples of PA steel were tested in two-outdoors exposure which produced, in only one year, a very effective passive patina. Consequently these tests clearly showed a vanishing effect of all staining contaminant products, meaning an outstanding advantage towards the environmental protection.

\section{References}

[1] K.G. Trubin and G.N. Oiks "Steel Making ". Mir Publishers. P. 553, (1974).

[2] E.S. Ayllón and B.M. Rosales, Revista Latinoamericana de Metalurgia y Materiales (Latin American Magazine on Metallurgy and Materials), $\underline{6}$, $\mathrm{N}^{\circ} 1$ and 2, p.49, (1986).

[3] A. Szummer and M. Janik-Czachor, Werkstoffe und Korrosion, 33, p.150, (1982).

[4] R. Zenarruja, H: Moral, H. Spira, G. Waellkens, E.Ribera, A. Borras, L. Ferro and H. Reggiardo, Comité de Acería (Steel Mill Committee), IAS, Chapter 2, p.55, (1983).

[5] E.S. Ayllón, S.L. Granese and B.M. Rosales, Corrosion Reviews, 9, $\mathrm{N}^{\circ} 3$ 4, p. 245 (1990).

[6] M. Pourbaix, Rapports Techniques, CEBELCOR, 109, R.T. 160 (1969).

[7] A. Fernandez, J.A. Navarro and B.M. Rosales, PROC, $4^{\circ}$ Congreso Iberoamericano de Corrosión y Protección, (4 Lantin American Congress on Corrosion and Protection), Mar del Plata, Argentina, 1, p.143, October 25th-30th (1992).

[8] S. Hoerlé, F. Mazaudier, Ph. Dillman and G. Santarini, Advances in understanding atmospheric corrosion, Corrosion Sci., 45, p.1431, (2004). 